Pak. j. sci. ind. res. Ser. A: phys. sci. 2017 60(3)134-140

\title{
Variability in Kernel Oil and Kernel Crude Protein Contents in Sudanese Fruit Accessions of Balanites aegyptiaca (L.) Del.
}

\author{
Nour Ahmed Osman-Bashir ${ }^{\mathrm{a}}$ and Salah Ahmed-Ali Elhussein ${ }^{\mathrm{b} *}$ \\ ${ }^{a}$ University College at Alwajh, University of Tabuk, Saudi Arabia \\ ${ }^{b}$ NOPRI, University of Gezira, Wad-Medani, Sudan \\ (received October 10, 2016; revised May 1, 2017; accepted June 14, 2017)
}

\begin{abstract}
Balanites fruits (Balanites aegyptiaca) as a potential source of steroidal sapogenins, chemicals in demand by the pharmaceutical industry was studied. This report focuses on two potential fruit products other than sapogenins, namely, balanites kernel oil (BKO) and kernel total protein. The oil content of balanites kernels obtained from thirteen mature-fruit accessions collected from different parts of Sudan was high, reaching a value above $40 \%$ of kernel dry weight in several accessions. Kernel total protein averaged $31.2 \%$. Some physicochemical characteristics of the oil and of its component lecithin fraction were determined. Linoleic acid was the predominant fatty acid in BKO, reaching $56.0 \%$ of total fatty acids.
\end{abstract}

Keywords: Balanites aegyptiaca, balanites kernel oil, fatty acids, kernel total protein

\section{Introduction}

Balanites aegyptiaca (L.) Del. of the plant family Zygophyllaceae is a wild, tropical, evergreen, xerophytic tree native to the Sudano-Sahielian regions of Africa and south Asia. The tree, known in Sudan as hijleej is branched, spiny, grows up to $10 \mathrm{~m}$ in height and has a more or less spherical crown. It is drought-resistant and has been suggested as suitable tree for planting to combat desertification (Gour and Kant, 2012). Balanites is locally valued in Sudan for its timber, edible fruit (mesocarp), animal feed value, shade and shelter and for several folk medicinal or nutraceutical uses, most notably is the use of the fruit mesocarp as an antidiabetic agent. A number of reports showed that various morphological parts of the tree are used in folk medicine on a world-wide scale (Chothani and Vaghasiya, 2011; Dubey et al., 2011; Yadav and Panghal, 2010).

The fruit, also known as desert date, is similar to the common date fruit in size and shape. It consists of a thin fragile yellowish brown skin (epicarp), covering a light to dark brown sticky pulp that is sweet in taste (the edible portion of the fruit). This pulp layer (mesocarp) encloses a hard, woody shell (endocarp) surrounding a light yellowish kernel, the morphological organ of interest in this study.

The most important chemical constituents of balanites tree, particularly its fruits, are the saponins. All saponins, whether possessing triterpenoid or steroid aglycones, are surface-active compounds that were shown to exhibit

\footnotetext{
*Author for correspondence; E-mail: salussein@gmail.com
}

a number of biological activities in animals (Francis et al., 2002), such as cytotoxicity (Podolak et al., 2010). Saponins of B. aegyptiaca, referred to as balanitins, are based on steroidal aglycones (steroidal sapogenins) and were shown to have in vitro antiproliferative activity against human cancer cells (Beit-Yannai et al., 2011), antitumor (Al-Ghannam et al., 2013) and molluscicidal activities (Molla et al., 2013; Liu and Nakanishi, 1982). It is historically noteworthy that one of the earliest reported biological activities of balanites fruit, a report on the usefulness of Sudanese laloab fruits for the control of schistosomiasis, was published as early as 1933 (Archibald, 1933). In addition to the above useful activities of potential medical applications, aqueous extracts (presumably of saponins) of fruits, roots, leaves and barks of balanites tree were shown to exhibit larvicidal activities towards mosquito larvae (Chapagain and Wiesman, 2005) as well as insecticidal effects against the mealy bug (Patil et al., 2010).

Steroidal sapogenins such as diosgenin, obtainable by hydrolysis of their corresponding saponin molecules, are used by the pharmaceutical industry as raw materials for the synthesis of oral contraceptives and other classes of steroid drugs (Hardman, 1987). The quest for economical plant sources of steroidal sapogenins other than Diocorea species, the only commercial source, pointed to the high potential of fruits of Balanites aegyptiaca as an alternative source (Hardman and Sofowora, 1972; 1970). Diosgenin and other steroidal sapogenins are also gaining increasing importance in view of their interesting biological activities, including 
anti-cancer (Raju and Bird,2007; Amin et al., 2005) and anti-diabetic effects (Hamza et al., 2012).

Currently fruits of balanites remain unexploited commercially for their valuable chemical products despite the fact that large amounts of edible fruit, sufficient to sustain commercial industrial utilization, are traditionally collected from wild trees and offered for sale in Sudanese local markets. Sudanese potential commercial sources of steroidal sapogenins are main research interest and the authors have previously reported on several accessions of Sudanese fenugreek seed as a promising source of steroidal sapogenins (Osman et al., 2014) and on the seed's major by-products such as oil, lecithin and protein (Osman-Bashir et al., 2015). Present research reports on another Sudanese sapogenin source, Balanites aegyptiaca, particularly the two important sapogenin by-products of the kernels, namely, balanites kernel oil (BKO) and kernel crude protein.

\section{Materials and Methods}

Plant material. Ripe fruits of Balanites aegyptiaca (edible, market stage) were collected from wild trees growing in the geographical zones of Sudan appropriately indicated in (Table 1-2). Fruit kernels were separated after gentle hand hammering of the fruits. Accession 1 (Table 1) was used for the characterisation of balanites kernel oil (BKO)

Chemicals: All solvents and chemicals used were of analytical laboratory grade.

Fixed oil and crude protein determination. Balanites kernel oil (BKO) was prepared by extracting powdered kernel material in a Soxhlet apparatus for $6 \mathrm{~h}$, using nhexane as solvent. The marc left was used for crude protein determination by the Kjeldahl sulphuric acid digestion method, multiplying the figure obtained for total nitrogen content by a factor of 6.25 (AOAC, 1990). Values for both fixed oil and crude protein content were expressed on an oven-dry seed-weight basis.

Oil physicochemical constants. The iodine value, saponification value, unsaponifiable matter, peroxide value and acid value were determined according to standard methods of AOAC (1990).

Preparation of the oil lecithin fraction. Isolation of the lecithin fraction from BKO was carried out as previously described by Osman-Bashir et al. (2015). The method consisted of mixing the oil with a little amount of water to hydrate the phospholipids, rendering them insoluble in the oil, followed by separating the precipitate (lecithin). Typically, to $5 \mathrm{~mL}$ of BKO, 0.1 $\mathrm{mL}$ of water ( $2 \%$ of oil volume) was added. The mixture was heated on a water bath at $75^{\circ} \mathrm{C}$ with thorough stirring for $15 \mathrm{~min}$. The lecithin fraction which precipitated from the rest of the oil on centrifugation (3000 rpm: $15 \mathrm{~min}$ ) was carefully washed with acetone, the residue of which was evaporated off before further analyses.

Thin-layer chromatography (TLC). Plates (20x20 $\mathrm{cm})$ pre-coated with silica gel $\mathrm{G} 60,0.2 \mathrm{~mm}$ thickness (Merck Co., Germany) were normally used. TLC plates used to separate triacylglycerol species of BKO and other oils by argentation TLC were manually prepared by making the slurry of silica gel in an aqueous $2.5 \%$ solution of silver nitrate before spreading and drying the plates. (This results in a 5.0\% silver nitrate content of the plates). Other conditions of the analysis are indicated in the legend to Fig. 1.

Gas liquid chromatography: For the preparation of fatty acid methyl esters, aliquots of BKO were dissolved in the methylation mixture methanol/ benzene/ conc. sulphuric acid (20: 10: 1) in Teflon capped sample tubes and heated at $75-80{ }^{\circ} \mathrm{C}$ for $90 \mathrm{~min}$. After allowing to cool, $4 \mathrm{~mL}$ of anhydrous sodium bicarbonate solution (5\%) was added and the mixture was twice extracted with hexane. Anhydrous sodium sulphate granules were added to the combined hexane layers containing the methyl esters before filtration and subsequent GLC analysis. A Varian Instrument Group Series 00-99714001 gas chromatograph equipped with a computing integrator was used for the analysis of fatty acid methyl esters. Analysis was carried out isothermally at column oven temperature of $170{ }^{\circ} \mathrm{C}$, column inlet and detector oven temperatures of $180^{\circ} \mathrm{C}$ and the carrier gas flow rate was $50 \mathrm{~mL} / \mathrm{min}$.

\section{Results and Discussion}

Physicochemical characteristics of BKO. Table 4 shows some of the oil constants of BKO obtained from mature-fruit accession number 1 (Table 1), procured from Wad-medani area in central Sudan. The oil content of the kernels of this accession was $46.0 \%$. Physicochemical characteristics found for BKO of this fruit accession were in general agreement with those reported by Manji et al. (2013), and Arora and Tak (2013) and Hussein et al. (1949). On the other hand, the iodine value calculated as an average for six 
accessions (125.3 g iodine per $100 \mathrm{~g}$, Table 4) in the present study was higher than the corresponding values reported by other investigators, which were $78.7 \mathrm{~g}$ iodine per $100 \mathrm{~g}$ for Nigerian fruits (Manji et al., 2013) and 96.0-106.0 $\mathrm{g}$ iodine per $100 \mathrm{~g}$ for Indian fruits (Arora and Tak, 2013). Hussein et al. (1949) had reported a higher iodine value for BKO obtained from Sudanese fruits compared to those from Ugandan or Nigerian

Table 1. Oil and moisture contents of balanites kernels of fruit accessions collected from different regions of Sudan.

\begin{tabular}{lll}
\hline \hline $\begin{array}{l}\text { Fruit collection area (nearest } \\
\text { town/ region of Sudan) }\end{array}$ & $\begin{array}{l}\text { Kernel oil } \\
\text { \%, on oven- } \\
\text { dry wt. basis }\end{array}$ & $\begin{array}{l}\text { Kernel } \\
\text { moisture } \\
\text { content }\end{array}$ \\
\hline Wad-medani/ Central region & 46.0 & 3.0 \\
Wad-medani/ Central & 46.0 & 3.5 \\
Alhasahisa/ Central & 45.3 & 4.0 \\
Wad-alnayal/ Central & 43.6 & 2.3 \\
Aldamazin/ South eastern & 43.3 & 4.0 \\
Alroseris/ South eastern & 33.0 & 1.7 \\
Alobayid/ Western & 43.0 & 1.0 \\
Alobayid/ Western & 41.0 & 2.3 \\
Alobayid/ Western & 45.5 & 3.5 \\
Alfashir/ Western & 36.0 & 2.9 \\
Alfashir/ Western & 23.0 & 4.0 \\
Kasala/ Eastern & 48.8 & 3.9 \\
Malakal/ Southern & 42.9 & 7.0 \\
\hline \hline
\end{tabular}

Table 2. Crude protein content of kernels separated from balanites fruit accessions collected from different localities in Sudan.

\begin{tabular}{ll}
\hline \hline $\begin{array}{l}\text { Fruit collection area } \\
\text { (nearest town/ region of }\end{array}$ & $\begin{array}{l}\text { Total crude protein } \\
\text { content, \% on kernel } \\
\text { dry-wt basis }\end{array}$ \\
\hline Wad-medani/ Central region & 35.0 \\
Wad-medani/ Central & 26.3 \\
Wad-medani/ Central & 29.8 \\
Alroseris/ South east & 31.1 \\
Alobayid/ Western & 28.9 \\
Alobayid/ Western & 34.1 \\
Alobayid/ Western & 28.9 \\
Alobayid/ Western & 35.5 \\
Umrowaba/ Western & 31.5 \\
Alfashir/ Western & 42.8 \\
Kasala/ Eastern & 27.1 \\
Malakal/ Southern & 28.0 \\
Malakal/ Southern & 27.1 \\
\hline \hline
\end{tabular}

fruits (102.2 cf 98.0 and 92.5). The variability observed in acid value, of course, reflects post-harvest conditions to which the fruits were subjected.

Fatty acid composition of BKO from mature fruits. Table 3 shows the fatty acid composition of BKO extracted from mature fruits of accession 1. The major fatty acids i.e., palmitic, stearic, oleic and linoleic acids are in agreement with earlier reports ( Arora and Tak, 2013; Gour and Kant, 2012; Chapagain et al., 2009; Mohamed et al., 2002; Abu-El-Futuh, 1983). The most predominant fatty acid of this accession was linoleic acid (56.0\% of total BKO fatty acids, Table 3$)$. This is in good agreement with the reports of of Chapagain et al. (2009) and Mohamed et al. (2002), confirming the fact that $\mathrm{BKO}$ is a high linoleate type of oil. On the other hand two studies, one on Indian and the other on Sudanese fruits, reported a slight dominance of oleic over linoleic acid (Arora and Tak, 2013; Abu-El-Futuh, 1983). In addition to these fatty acids, Arora and Tak (2013) also reported the occurrence of palmitoleic and linolenic acids in small amounts $(2.24 \%$ and $2.84 \%$, respectively) in BKO of Indian origin.

The fatty acid composition of the fruit kernel oil of $B$. aegyptiaca is somewhat variable. Such variation, among the accessions may indirectly be revealed by differences in iodine values and perhaps refractive indices found for some accessions in the present study (Table 4).

Separation of triacylglycerol species by argentation thin-layer chromatography (Fig. 1) shows that BKO is more similar to normal oils in edible use such as ground nut oil, than the more saturated oils tested (palm oil and its derived fractions, palm stearin and palm olein).

BKO lecithin. Lecithins, natural emulsifiers employed by the food and pharmaceutical industries, are mainly composed of phospholipids, the minor components being steroid derivatives, glycolipids and pigments (Cherry and Kramer, 1989).

Table 5 shows that BKO of accession 1 contained a moderate amount $(3.0 \%$ of oil volume, $\mathrm{w} / \mathrm{v})$ of a creamy coloured lecithin fraction having an iodine value somewhat higher than that exhibited by the total kernel oil (148.0 cf. 125.3, Tables 4-5). Although not completely dried and purified, the value found for BKO compares favourably with that reported by Cherry and Kramer, (1989) for soybean oil (2.3\% phospholipids, by weight of crude soybean oil), currently the major commercial source of lecithin. 
Table 3. Fatty acid composition of BKO of accession 1.

\begin{tabular}{ll}
\hline \hline Fatty acid & $\%$ \\
\hline Palmitic & 8.2 \\
Stearic & 10.0 \\
Oleic & 25.4 \\
Linoleic & 56.0 \\
Linolenic & 0.2 \\
Others & 0.2 \\
\hline \hline
\end{tabular}

Variability in oil content of different fruit accessions of Balanites aegyptiaca. Kernels of balanites fruit

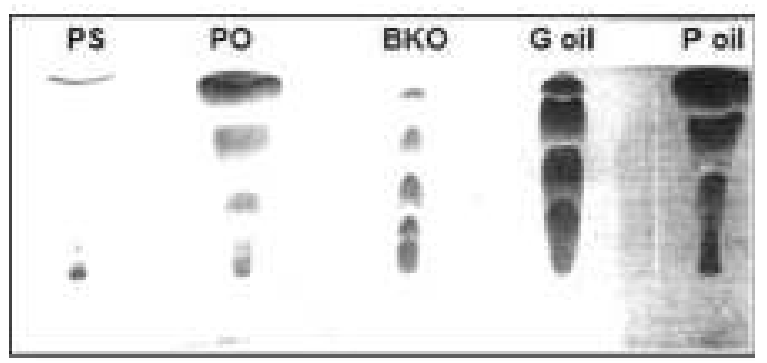

Fig 1. Separation of triacylglycerol species of balanites kernel oil and other commonseed oils by ArgentationTLC. abbreviations: PS $=$ palm stearin, $\mathrm{PO}=$ palm olein, $\mathrm{BKO}=$ balanites kernel oil, G oil = ground nut oil, $\mathrm{P}$ oil $=$ palm oil, Adsorbent $=5 \%$ siliver nitrate in silica gel, detection $=$ sulphuric acid, $50 \%$, heating at $100{ }^{\circ} \mathrm{C}$. solvent system: diethyl ether, hexane $=(1: 2)$.

Table 4. Physicochemical characteristics of BKO obtained from accession 1.

\begin{tabular}{ll}
\hline \hline Characteristic & Value \\
\hline Oil content $(\%$ of kernel dry weight) & 46.0 \\
Refractive index $\left(20^{\circ}\right)$ & $1.472 *^{1}$ \\
Iodine value $(\mathrm{g}$ iodine $/ 100 \mathrm{~g})$ & $125.3 *^{2}$ \\
Peroxide value & 5.6 \\
Saponification value $(\mathrm{mg} \mathrm{KOH} / \mathrm{g})$ & 198.9 \\
Acid value $(\mathrm{mg} \mathrm{KOH} / \mathrm{g})$ & 2.2 \\
Unsaponifiable matter $(\%)$ & 0.46 \\
\hline \hline
\end{tabular}

* 1 , The value for 11 accessions varied between 1.4712 (for SE Sudan accession) and 1.4731 (for south Sudan accession); *2, The value for 6 accessions varied between 107.9 (central Sudan accession) and 135.9 (western Sudan accession). accessions obtained from different parts of Sudan were rich in fixed oil (Table 1). Most values exceeded 40.0\%, on an oven dry- weight basis. This agrees well with other studies which analysed single or multiple accessions of African or Indian origin and show that balanites fruit kernels are rich source of fixed oil. These other studies reported kernel oil contents of 40-42.1\% (Arora and Tak, 2013); 46.5\% (Manji et al., 2013); 30.0-60.0\% (Gour and Kant, 2012); 46.7\% (Chapagain et al., 2009); 49.9\% (Mohamed et al., 2002) and 49.0\% (Hussein et al., 1949). However, comparatively lower kernel oil content values were occasionally encountered.

Table 1 contains fruit accessions with BKO values lower than $40 \%$, particularly accession 11 , procured from western Sudan, which exhibited a value of only 23.0 $\%$. An earlier work (Elfeel, 2010) reported a BKO oil content as low as $20.0 \%$ (and as high as $50.0 \%$ ) in a study of three balanites fruit accessions from central, western and southern regions of Sudan.

Occurrence of oil in the woody part (endocarp). Balanites fruit morphological parts other than the kernel are not known to contain appreciable amounts of fixed oil. However, while studying sapogenins in different morphological parts of balanites fruit, it was oberserved that a considerable proportion of fixed oil was present in the woody tissue surrounding the kernels (the endocarp). This oil amounted to $5.0 \%$ of the dry weight of the woody part of mature fruits of accession 1. Ongoing studies by the authors show that this oil content was even higher in younger fruit developmental stages. This inherent oil would add to the calorific value of the endocarp, a woody tissue already reported to have a high bio-carbon yield making it suitable for use as a fuel (Elfeel and Hindi, 2014).

Total kernel crude protein content of different accessions of balanites fruits. The total crude protein of balanites kernels ranged between $26.3 \%$ and $42.8 \%$ in the 13 fruit accessions collected from different parts

Table 5. Some physicochemical characteristics of BKO lecithin of accession 1 .

\begin{tabular}{ll}
\hline \hline Parameter & Result \\
\hline$\%$ of oil volume $(\mathrm{w} / \mathrm{v})$ & 3.0 \\
Colour & Creamy \\
Consistency description & Light \\
Free fatty acids (\%) & 0.11 \\
Iodine value (g iodine $/ 100 \mathrm{~g})$ & 148.0 \\
\hline \hline
\end{tabular}


of Sudan (Table 2), the average being 31.2\%. These results are in close agreement with the value of $32.4 \%$ reported by Mohamed et al. (2002) for kernel protein of one Sudanese fruit accession and with the range of 27.0-37.0 found by Elfeel (2010) for three Sudanese accessions.

The potential for commercialization of balanites chemical products. Balanites fruits contain several chemical constituents of potential industrial and medicinal applications especially steroidal sapogenins and biological activities associated with fruit extracts. The potential for commercialisation of kernel oil and kernel protein has been discussed here, especially aspects of availability of raw material, BKO edibility and extraction protocol.

Balanites fruits collected from the wild constitute a local market commodity in Sudan and other African countries for the sugary fruit flesh (mesocarp). The pioneering work of Abu-El-Futuh (1983) estimated that about 400, 000 tonnes of fruit are annually collected for trading in Sudan alone. Increase in demand, beyond local edible use, would further boost local fruit collection. Yields of up to $125 \mathrm{~kg} /$ tree/ annum have been reported (Gour and Kant, 2012). Elfeel and Warrag (2011) estimated that more than 90 million trees grow wild in Sudan. Thus, sufficient quantities of wild-collected balanites fruit could sustain large scale diversified industrial utilization. Taking into account that kernel tissue represents one-tenth of whole fruit weight (Hussein et al., 1949), large-scale commercial production of BKO approaching the range of hundred-thousand tonnage per annum is possible. Proper agricultural (silvicultural) intervention would further increase fruit harvest, including programmes on management and breeding to solve problems such the prolonged fruiting season and control of insects reported to parasitize on fruit kernel tissue (Hussein et al., 1949) as well as quantitative and qualitative manipulation of chemical content, given the considerable variability shown among fruit accession from wild stands.

In south-western Sudan BKO is locally prepared for edible purposes by stone-crushing the fruits, grinding in a native mortar and stirring in boiling water. The floating oil layer is separated and the oil further boiled to remove traces of water (Elfeel and Warrag, 2011; Abu-El-Futuh 1983). The bitter polar components of the kernels, the saponins, presumably remain in the water phase. In the present study, the hexane extracted
BKO was organoleptically free of any bitterness and infra-red spectroscopic analysis of this oil showed the lack of any spirostan absorption characteristic of sapogenins. Efficient extraction of the pharmaceutically valuable steroidal sapogenins from balanites kernels requires pre-defatting of the tissue using solvents such as hexane. Thus edible BKO could be recovered as a by-product in this sequential extraction protocol. Lecithins, if proved valuable, could subsequently be extracted during oil refining. Even if BKO is not utilized for edible purposes it stands another chance of being utilized as a biodiesel (Chapagain et al., 2009).

Balanites kernels generally contain a total crude protein of around $30 \%$ (Table 2). Some authors held the opinion that the presence of the bitter-tasting saponins is a problem limiting the utilization of kernel protein by humans and animals (Mohamed et al., 2002). However, Abu-El-Futuh (1983) demonstrated that edible (nonbitter) nuts for human consumption could be prepared by boiling balanites kernels in a process involving four changes of the water, followed by drying the resulting de-bittered kernels. However, the above method gave no consideration for recovery of the valuable sapogenins. Even non-debittered balanites kernel cake, at the level of $30 \%$ of the feed, was reported to be as good as cotton seed cake for fattening sheep without any toxic effect observed in these animals (El Khidir et al., 1983). A sequential extraction scheme, therefore, needs to be further developed in order to recover oil, protein and sapogenins of the kernel, sapogenins of the mesocarp and epicarp as well as other little-characterized components of the fruit implicated in some biological activities of potential use.

\section{References}

Abu-El-Futuh, I.M. 1983. Balanites aegyptiaca, An Unutilized Raw Material Potentially Ready for Agro-industrial Exploitation. United Nations Industrial Development Organization, Vienna, Austria. UNIDO Document no. 12419, Project TF/INT/77/021.

Al-Ghannam, S.M., Ahmed, H.H., Zein, N., Zahran, F. 2013. Antitumor activity of balanitoside from Balanites aegyptiaca fruit. Journal of Applied Pharmaceutical Science, 3: 179-191.

Amin, A., Alkaabi, A., Al-Falasi, S., Daoud, S.A. 2005. Chemopreventive activities of Trigonella foenumgraecum (Fenugreek) against breast cancer. Cell Biology International, 29: 687-694. 
AOAC, 1990. Official Methods of Analysis, $15^{\text {th }}$ edition, Association of Official Analytical Chemists Washington, USA.

Archibald, R.G. 1933. The use of the fruit of the tree Balanites aegyptiaca in the control of schistosomiasis in the Sudan. Transactions of the Royal Society of Tropical Medicine and Hygiene, 27: 207-210.

Arora, A., Tak, L. 2013. Balanites roxburghii, Physicochemical properties and composition of fatty acid from arid zone of Rajasthan. International Journal of Basic and Applied Chemical Sciences, 3: 1-5.

Beit-Yannai, E., Ben-Shabat, S., Goldschmidt, N., Chapagain, B.P., Liu, R.H., Wiesman, Z. 2011. Antiproliferative activity of saponins from Balanites aegyptiaca- an in vitro study. Phytochemistry Letters, 4: 43-47.

Chapagain, B.P., Yehoshua, Y., Wiesman, Z. 2009. Desert date (Balanites aegyptiaca) as an arid lands sustainable bioresource for biodiesel. Bioresource Technology, 100: 1221-1226.

Chapagain, B., Wiesman, Z. 2005. Larvicidal effect of aqueous extracts of Balanites aegyptiaca (desert date) against the larvae of Culex pipiens mosquitoes. African Journal of Biotechnology, 4: 1351-1354.

Cherry, J.P., Kramer, W.H. 1989. Plant Sources of Lecithins. In: Lecithins: Sources, Manufacture and Uses, B.F. Szuhaj (ed), pp 16-31, AOCS, Champaigne, IL., USA.

Chothani, D.L., Vaghasiya, H.U. 2011. A review of Balanites aegyptiaca Del (desert date): phytochemical constituents, traditional uses and pharmacological activity. Pharmacognosy Review, 5: 55-62.

Dubey, P.K., Yogi, M., Bharadwaj, A., Soni, M.L., Singh, A., Sachan, A.K. 2011. Balanites aegyptiaca (L.) Del., a semi-arid forest tree: a review. Academic Journal of Plant Sciences, 4: 12-18.

El Khidir, O.A., Gumaa, A.Y., Fangali, O.A.I., Badir, N.A. 1983. The use of Balanites kernel cake in a diet for fattening sheep. Animal Feed Science and Technology, 9: 301-306.

Elfeel, A.A., Hindi, S.Z. 2014. Balanites aegyptiaca (L.) Del. var. aegyptiaca seed composition and variability among three different intraspecific sources. Life Science Journal, 11: 160-166.

Elfeel, A.A., Warrag, E.I. 2011. Uses and conservation status of Balanites aegyptiaca (L.) Del. (Hegleig Tree) in Sudan: Local people perspective. Asian Journal of Agricultural Sciences, 3: 286-290.

Elfeel, A.A. 2010. Variability in Balanites aegyptiaca var. aegyptiaca seed kernel oil, protein and mineral contents between and within locations. Agricultural and Biology Journal of North America, 1: 170-174.

Francis, G., Kerem, Z., Makkar, H.P.S., Becker, K. 2002. The biological action of saponins in animal systems: a review. British Journal of Nutrition, 88: 587-605.

Gour, V.S., Kant, T. 2012. Balanites aegyptiaca (L.) Del.: a multipurpose and potential biodiesel tree species of the arid regions. International Journal of Science and Nature, 3: 472-475.

Hamza, N., Berhe, B., Cheze, Z., Le Garrec, R., Umar, A., Agli, A.N., Lassalle, R., Jove, J., Gin, N., Moore, N. 2012. Preventive and curative effect of Trigonella foenum-graecum L. seeds in C57BL/BJ models of type 2 diabetes induced by high-fat diet. Journal of Ethnopharmacology, 142: 516-522.

Hardman, R. 1987. Recent developments in our knowledge of steroids (a review). Planta Medica, 53: 233-238.

Hardman, R., Sofowora, E.A. 1972. A reinvestigation of Balanites aegyptiaca as a source of steroidal sapogenins. Economic Botany, 26: 169-173.

Hardman, R., Sofowora, E.A. 1970. Isolation and characterization of yamogenin from Balanites aegyptiaca. Phytochemistry, 9: 645-649.

Hussein, S.A., Dollear, F.G., O’conner, R. 1949. Oil from the kernels of laloab fruit, Balanites aegyptiaca. Journal of the American Oil Chemists' Society, 26: 730-732.

Liu, H.W., Nakanishi, K. 1982. The structures of balanitins, potent molluscicides isolated from Balanites aegyptiaca. Tetrahedron, 38: 513-519.

Manji, A.J., Sara, E.E., Modibbo, U.U. 2013. Studies on the potentials of Balanites aegyptiaca seed oil as raw material for the production of liquid cleansing agents. International Journal of Physical Sciences, 8: $1655-1660$.

Mohamed, A.M., Wolf, W., Spiess, W.E.L. 2002. Physical, morphological and chemical characteristics, oil recovery and fatty acid composition of Balanites aegyptiaca Del. kernels. Plant Foods for Human Nutrition, 57: 179-189.

Molla, E., Giday, M., Erko, B. 2013. Laboratory assessment of the molluscicidal and cercariacidal activities of Balanites aegyptiaca. Asian Pacific Journal of Tropical Biomedicine, 3: 657-662.

Osman-Bashir, N.A., Elhussein, S.A., Taha, A.A. 2015. Content of crude protein, fixed oil and lecithin in Sudanese seed accessions of fenugreek (Trigonella foenumgraecum L.). Pakistan Journal of Nutrition, 14: 907-912. 
Osman, N.A., Elhussein, S.A., Albalawi, M.A.D. 2014. Variability in the content of $25 \alpha$ - and $25 \beta$ - steroidal sapogenins among thirty morphologically different Sudanese seed accessions of fenugreek. Journal of Life Sciences, 8: 744-757.

Patil, S.V., Salunke, B.K., Patil, C.D., Salunkhe, P.B., Gavit, P., Maheshwari, V.L. 2010. Potential of extracts of the tropical plant Balanites aegyptiaca (L) Del (Balanitaceae) to control the mealy bug, Maconellicoccus hirsutus (Homoptera: Pseudococcidae). Crop Protection, 29: 1293-1296.

Podolak, I., Galanty, A., Sobolewska, D. 2010. Saponins as cytotoxic agents: a review. Phytochemistry Reviews, 9: 425-474.

Raju, J., Bird, R.R. 2007. Diosgenin, a naturally occurring furostanol saponin, suppresses 3-hydroxy3-methylglutaryl CoA reductase expression and induces apoptosis in HCT-116 human colon carcinoma cells. Cancer Letters, 255: 194-204.

Yadav, J.P, Panghal, M. 2010. Balanites aegyptiaca (L) Del.(Hingot): A review of its traditional uses, phytochemistry and pharmacological properties. International Journal of Green Pharmacy, 4: 140146. 